\title{
e-Portfolio: a tool to assess University students' skills
}

\author{
Silvia Rodriguez-Donaire \\ Dept. de Organización de Empresas \\ Universidad Politécnica de Cataluña, UPC \\ Terrassa, Barcelona, Spain \\ silvia.rodriguez-donaire@upc.edu
}

\author{
Beatriz Amante García \\ Dept. Proyectos de Ingeniería \\ Universidad Politécnica de Cataluña, UPC \\ Terrassa, Barcelona, Spain \\ beatriz.amante@upc.edu
}

\author{
Sonia Oliver del Olmo \\ Dept. de Filología Inglesa y Germanística \\ UAB, Campus Bellaterra, Barcelona, Spain \\ sonia.oliver@uab.cat
}

\begin{abstract}
The present article introduces the main qualitative and quantitative results obtained in a pilot study of eportfolio implementation in two different subjects offered in the Polytechnic University of Catalonia (Universitat Politècnica de Catalunya, UPC). In particular, such teaching innovation took place within the Technical Industrial and Aeronautics Engineering School (ETSEIAT) curricula. And our results seem to indicate that the e-Portfolio can be viewed as: 1) a complementary tool for student's assessment and 2) a perfect follow-up device to check student's competences development (both generic and specific) throughout their degree studies. The useful data gathered allow us to generalize our findings and therefore, consider its implementation in the second cycle of Industrial Organization (IO) Engineering as well as the rest of degrees taught at the UPC.
\end{abstract}

Keywords - student's competences assessment, collaborative tools, e-Portfolio, Web2.0, European Higher Education Area (EHEA), teaching innovation

\section{Introduction}

The present paper aims at analyzing the use of the electronic Portfolio, also known as e-Portfolio or digital Portfolio, within the University degrees of IO Engineering offered at the ETSEIAT in Terrassa (Barcelona) of the UPC. This study has been carried out through a close observation of a totally free platform as Google Sites is.

The e-Portfolio derives from the written version of a portfolio, which has been frequently used throughout the last decades so as to develop and assess both personal and professional activities. The main difference, then, between a traditional portfolio and the new e-portfolio is the ease to publish contents and/or evidence in electronic format in the net, besides from sharing one's ideas with other online users during the same process of reflection.

Until now, the porfolio was only used as a collector of student's or professor's evidence throughout the different academic years. But now, evidence on the real possibilities of these tools is immediately gathered through the use of collaborative platforms, in terms of teaching quality. These new environments facilitate new methodologies of assessment on student's competences learning and acquisition [2][5].

The emergence and use of collaborative tools as well as Internet platforms, which enhance users' information sharing, for instance BSCW (Basic Support for Collaborative Work), Google Docs, Google Sites, or Moodle, among others, have caused many changes in the traditional methods as such shared workspace servers. These latter ones are viewed now as a complementary element to identify new learning methodologies. The existence of these digital environments aids university teaching practice and enhances taking advantage of the Web2.0 use at the same time. Besides, the use of these platforms encourages and facilitates students', professors' and other users' participation by collaborating and sharing knowledge and information. All these tools, thus, simplify the access, sharing and creation of new knowledge and increase the productivity and flexibility of collaborative work. [8] and [9]. The above mention factors are, then, key for the successful development 
and implementation of the methodology in which the present study is based on.

Within the education field there are numerous researchers who have confirmed the usefulness of the e-Portfolio in the learning processes, as well as in the development and assessment of student's competences in terms of evaluating this new method's efficiency as a formative tool (e.g. [4], [5]). An illustrative point could be that many professors worldwide are implementing new assessment methodologies which go beyond the routinary standard and multiple choice tests and incorporate activities in which students have to prove their skills when solving problems, reflecting, analyzing and synthesizing as in the case of the ePorfolio's use and development.

So far, we have found two main factors that show that the e-Portfolio could become an excellent complementary tool for assessing student's competences within the Spanish universities' new Degrees' framework, as:

1) It enhances learning through a process in which the student has to develop, collaborate and pay attention to professors' comments [7].

2) Its use simplifies the learning of formative goals and assesses all what the student has learnt throughout the academic course as to summative goals is concerned [1] and [6].

In addition, we would like to incorporate a third factor that could aid the evaluation of the student's global learning process (taking into account a complete formative cycle). Taking advantage of the current changes that are taking place due to the new Degrees' system implementation:

3) The cross-curricular or interdisciplinary use of the e-Portfolio

We believe that this latter factor can help evaluating the process of development and acquisition of competences nowadays required at university level.

On the other hand, it has been identified a gap in the specialized literature available on this topic, in other words, there hardly exist any publication with empirical results showing the effectiveness of this methodological tool. Therefore, in the present paper we will provide the reader with additional data which seem to confirm the usefulness of the e-Portfolio within the learning, development and assessment of student's competences by explaining our pilot experience in the ETSEIAT as an illustrative case of it.

In the following sections, then, we will describe the above mentioned pilot study focused on two subjects of second cycle in the IO Engineering degree of the
UPC. Later on, we will show the results obtained after assessing 69 e-Portfolios by means of an assessment rubric with 23 criteria. The rubric comprises 8 competences that any university student of the UPC requires, and more precisely, an Engineering student at the l'ETSEIAT. Moreover, we will also take into account UPC professors' view on the assessment of competences through the use of collaborative tools in the classroom. And finally, we will discuss our findings and possible further research in this field.

\section{2. e-Portfolio design activity}

\subsection{Strategy design}

So as to succeed in the implementation of the ePortfolio in the two subjects, professors had planned and designed a «customized » strategy according to the needs of each academic course in particular:

- Not overloading students with homework,

- $\quad$ Being aligned with the objectives of each course and degree,

- Adopted to every student's curriculum,

- Being completely accessible and zero cost,

- $\quad$ Being easy to use, and

- Suitable for any content and need of each subject

Additionally, this strategy includes the need to compile data on the perception of usefulness (or not) of the implemented methodology. A feedback provided both from students and professors. In this sense, all this inside information will be used to go on with the experimentation and incorporate elements of improvement in further editions.

This part of the study has been carried by means of a voluntary participation in a questionnaire addressed to students and professors of the ETSEIAT at UPC Tech, together with an e-Portfolio assessment rubric with 23 criteria. The latter, aims at providing objectivity on student's learning, and more precisely, on cross-curricular competences' acquisition throughout the whole process (see Appendix).

\subsection{Activity design}

In order to strictly follow the strategy that we have presented and thinking about the development of a criteria that will allow us, professors, to assess student's cross-curricular competences acquisition, we have created an e-Portfolio which is divided into the following parts: 
- A personal section in which students describe themselves, develop their Curriculum and write a letter of presentation. This part is designed bearing in mind the real needs of the student (i.e. generating an online $\mathrm{CV}$ ) or reflecting on one's future goals and professional interests, for example. The objective here is to encourage students' critical thinking and plan a strategy acquiring their professional interests.

- An introductory section in which students present a brief description of the subject in their own words. This introduction has to include the basic concepts covered in the course (core content of the subject), the objectives achieved as well as the time devoted to the subject and the development of the e-Portfolio. Through this section we guide students' analysis, synthesis and maturing of the knowledge acquired in the theory classes of the subject, reaching a level 2 of learning. ${ }^{1}$

- An application section in which students describe the implementation of one of the methods explained throughout the subject tuition together with a later reflection on the expected results. Every student will have, then, to design and apply his/her own study case based on his/her professional field. This part has been planned to motivate students and give an added value to the application and acquisition of the techniques studied in class.

This part compiles all the objectives of Bloom's taxonomy as students must use their knowledge (concepts), interpret it, and use it within their working environment. Therefore, students are asked to analyse the objectives of their case study so as to identify the best technique or method to be applied, foresee its possible consequences and predict results hypothetically. We are targeting here at following students' learning process step by step, namely, from acquiring a concept to developing critical thinking toward the expected results, reaching then a level 3 of learning.

- And a concluding section where students include a brief reflection on the usefulness of the e-Portfolio by taking into account the most relevant advantages and possible drawbacks of this new methodological tool. Besides, students carefully consider a personal improvement plan having in mind future subjects they will have to face. By this, we aim at developing student's critical thinking while

1 There are three different levels of learning coordinated by the Institute of Education Sciences (ICE) evaluating their own learning process in terms of ePortfolio production and flaw detection both in the tool and the methodology used. After this stage, students also achieve level 3 in their learning.

\subsection{Platform in use}

So as to carry out the present teaching experience we have used Google Sites (http:/sites.google.com), which is a structured wiki offered by Google as part of Google Applications since 2008. This platform allows creating web sites very simply without having to ask for a license, installation or maintenance of any kind of software or hardware. Google sites have a predetermined format which makes it easier for the user to create one and include credentials, academic homework from students and professors' comments. On the one hand, it offers "robustness" and it is easy to use and manage but on the other hand, designs are rather limited and restricted due to the little flexibility in terms of adding and organizing user's contents in them (e.g. texts, videos, images, etc.)

Some of the key features of this system are that the platform is designed to allow online collaborative work with other users, to have free access from anywhere in the net without having to duplicate contents and to integrate collaborative tools, such as blogs, videos, wikis, etc. In this sense, gaining access to other existing materials becomes more efficient and effective. As a result, Google sites pays off the advantages of Web2.0's philosophy as they allow users to create, collaborate and share documents, ideas and opinions besides from adding multimedia contents in their sites (i.e. including social markers, posting files in any format and having the possibility of personalizing data). However, forum discussions among students are not permitted.

Nevertheless, all the above mentioned advantages enhance students' autonomy as to e-Portfolio design becoming, then, responsible of their own materials and contents and the later maintenance of the site. In addition, professors can assess contents and provide students with constant feedback which, at the same time, helps them develop their critical thinking and facilitates their generic competences' acquisition.

\section{Methodology}

\subsection{Pilot Experience}

The main objective of this pilot experience is studying the potential of the e-Portfolio as a tool for helping students improve their learning and making them capable of assessing the level of cross-curricular competences achieved. By definition, thereby, we have 
avoided any additional resource in terms of money or extra infrastructures guaranteeing as well the minimum time investment for the learning and the development of the webs that guide the creative process of students' e-Portfolios.

More precisely, the cross-curricular competences that we target in the two subjects under study coincide with a subgroup of 8 competences required to any UPC student, and they are: autonomous learning, efficient use of information sources, synthesis and analysis (critical thinking and decision making), innovation and creativity, sustainability and social commitment, oral and written communication in a third language (English) and team work (specifically, e-portfolio sharing)

\section{2. e- Portfolio Assessment Results}

In this section we will present the results of the survey carried out among ETSEIAT professors, as we have previously mentioned, a Technical School that belongs to the UPC. Teaching staff were asked about their views on students' competences assessment through the use of this new methodology and had also to provide feedback on the results obtained after the application of the evaluation criteria given when developing the activity.

3.2.1. Professors' views on students' skills development through the use of the e-Portfolio. A 50 question survey was sent electronically using a distribution list from the teaching staff in the UPC. By doing this, we aimed at figuring out how many professors were actually using collaborative environments to develop students' specific and/or generic competences and, more precisely, through the e-Portfolio. At this stage, we must mention that 40 professors participated, which means approximately a fourth of the total staff in our University. When analyzing the results obtained, we observed that $67 \%$ of the participants do not use online collaborative tools in the classroom. In a sense, this result could be easily explained if we bear in mind that $59 \%$ of the professors who answered the questionnaire are older than 40 .

But turning now into the sample of professors who use collaborative tools (Wikis, BSCW, Google Sites and others) to improve their students' learning process, we observe that the most common environment is Google Sites (Fig. 1). In addition, professors' views on their students' use of collaborative environments show that $92 \%$ of the teaching staff claim that their students are satisfied with it (Fig. 2) and 69\% think that their students will use such platforms (a lot or quite a lot) when the academic year is over.

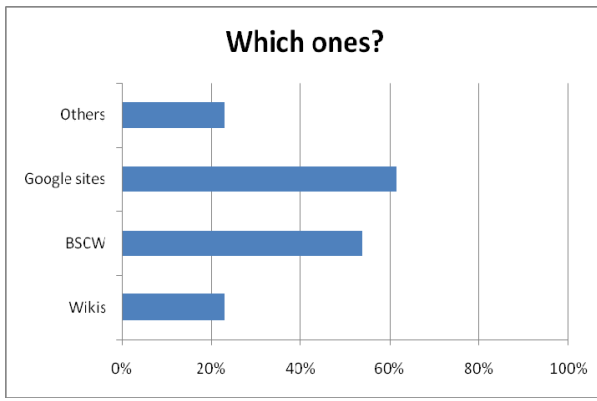

Figure1.Collaborative Systems in use (Teachers' e-Portfolio survey source)

Another important point is students' ownership of the collaborative space used as in $92 \%$ of the cases where professors use such environment to improve the learning process, students themselves own it.

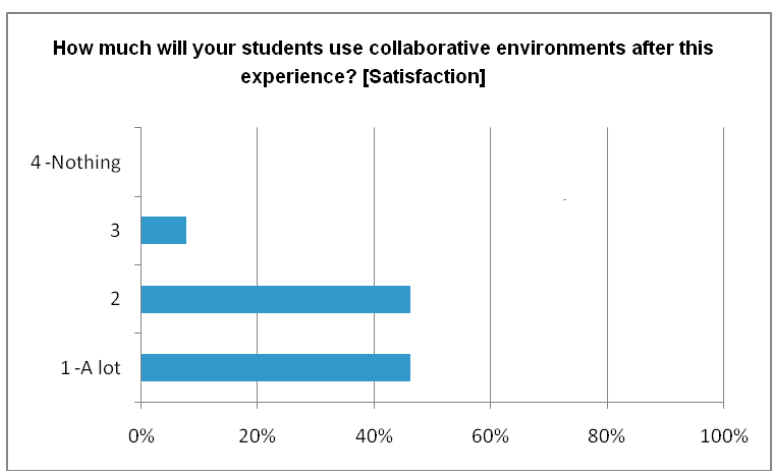

Figure 2. Professors' views on students' skills development through the use of the e-Portolio (Teachers' e-Portfolio survey source)

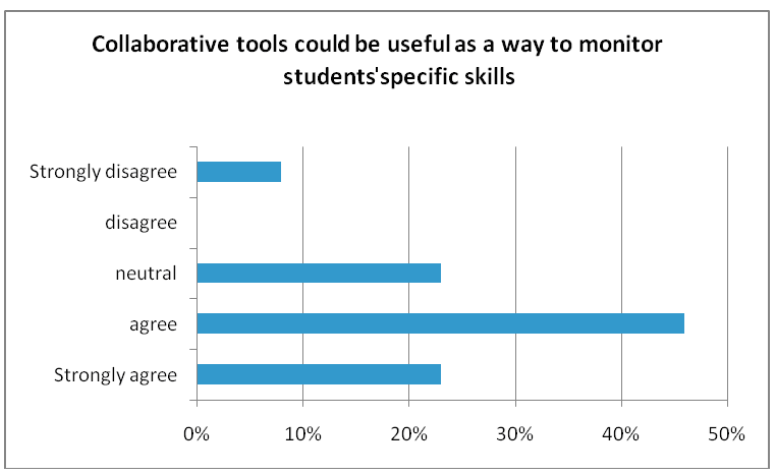

Figure 3. Collaborative tools could be useful as a way to monitor students' specific skills (Teachers' e-Portfolio survey source)

We would like to mention here that when professors were asked if collaborative environments were useful for students' generic competences development, $77 \%$ of them showed agreement (considering strongly agree and agree answers), and in the case of specific competences' acquisition $69 \%$ of them agreed. In Figure 3, we can see the percentage of teaching staff that consider collaborative tools useful for monitoring students' progress in specific skills. 
In the following Figure 4, we can clearly see to which extent professors think students' competences can be enhanced through the use of these collaborative environments.

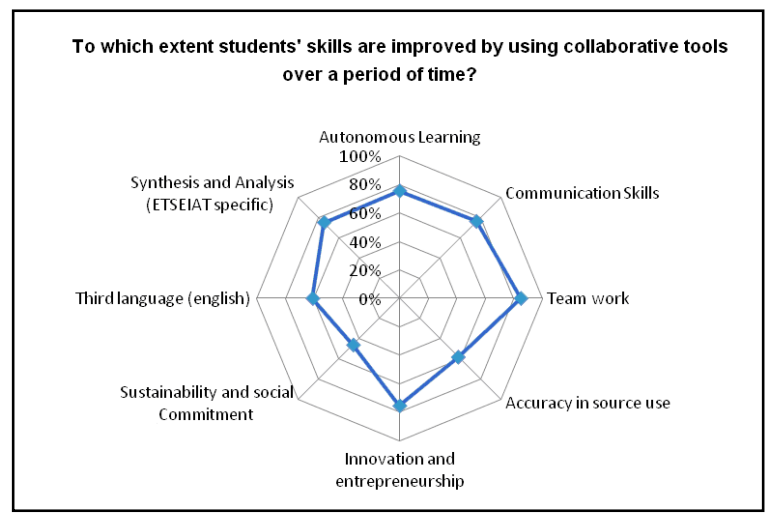

Figure 4. Professors' views on the development and control of generic competences acquisition through the use of collaborative environments.(Teachers' e-Portfolio survey source)

The latter questions in the survey are more focused in the usefulness of the e-Portfolio as a tool for students' competences development. In these sense, our results indicate that $100 \%$ of the professors think that Google Sites can be a good tool and 50\% of them claim that they had already experimented with this new environment in their classes. In addition, $100 \%$ of the teaching staff surveyed think that their students found the experience very positive.

3.2.2. Assessing students' skills through the use of the e-Portfolio. After applying the set rubrics of competences in our students' e-Portfolios (a total sample of 69 e-Portfolios), we have observed that the competences most developed by our students are written communication skills $(88 \%)$, oral communication skills (84\%), decision making (84\%) and the efficient use of information sources $(83 \%)$ ).

From these data, we would like to highlight the decision making competence result as we could see three main causes in here: (1) students are in their last academic year of their Engineering studies; (2) In their curriculum, organizing, understanding and analyzing varied situations are key issues (IO Engineering); and (3) the subjects where this e-Portfolio implementation has been carried out aim at students' application of the knowledge acquired in class into their professional careers.

In other words, students are asked to apply the most suitable mathematical method to solve a real problem in their professional careers or/and to manage, plan and develop a project. These two activities encourage decision making competence as students have to use their reasoning skills properly. A good reflection, analysis and understanding of the problem allow students to solve the case by choosing the best strategy available. Not to mention, choosing one or another option will enhance students' critical thinking being the latter one of the least developed abilities in Engineering studies. Therefore, with our methodological innovation we have tried to motivate students by improving their reflection on which decision to be made and why depending on the study case.

Innovation and creativity competences as well as collaborative/sharing e-Portfolios have obtained results below $50 \%$ after applying the rubrics. If we take into consideration that creativity measures the design and ease of access of the e-Portfolio and collaboration is focused on students' opinions on the fact of sharing their knowledge with others, these results are not that surprising.

As to the assessment of oral communication skills within the e-Portfolio implementation activity, we must say that all the data gathered comes from the analysis of the oral presentations developed and the videos students produce while attending Projects subject. The latter, must be consider part of student's evidence in the e-Portfolio.

Focusing now on the rest of the competences, we could add that the efficient use of information (re)sources will measure the correct use of sources citation within the contents as well as the reliability of the links from the Internet. Not to mention, the quality and interpretation of the resources are key to properly acquire such skill. On the other hand, in the sustainability and social commitment competences we try to assess students' ability to spread knowledge and their good practice in terms of actively contributing to the development of the course/subject.

Nowadays, the UPC is changing the model of traditional tuition into a more co-operative and collaborative one, in other words, students become the centre of the learning process and, therefore, the main scope of the course's design. Finally, and related to the written communication skill, we would like to mention that while evaluating students' degree of this competence we were basically concentrating on how contents were structured, their relevance on the topic per se and the format that students used (Table I). 
TABLE I. RESULTS OF COMPETENCES’ ASSESSMENT (23 criteria)

\begin{tabular}{|l|c|}
\hline Skills & Percentage \\
\hline Autonomous learning & $64,28 \%$ \\
\hline Decision making & $84,20 \%$ \\
\hline Critical Thinking & $51,01 \%$ \\
\hline Innovation and Creativity & $49,86 \%$ \\
\hline Oral communication skills & $84,17 \%$ \\
\hline Team work (ePortfolio sharing) & $47,17 \%$ \\
\hline $\begin{array}{l}\text { Efficient use of information } \\
\text { sources }\end{array}$ & $83,82 \%$ \\
\hline Written communication skills & $88,04 \%$ \\
\hline $\begin{array}{l}\text { Sustainability and social } \\
\text { commitment }\end{array}$ & $73,48 \%$ \\
\hline
\end{tabular}

In Figure 5 we have compiled all the data related to the distribution of results in Table I above.

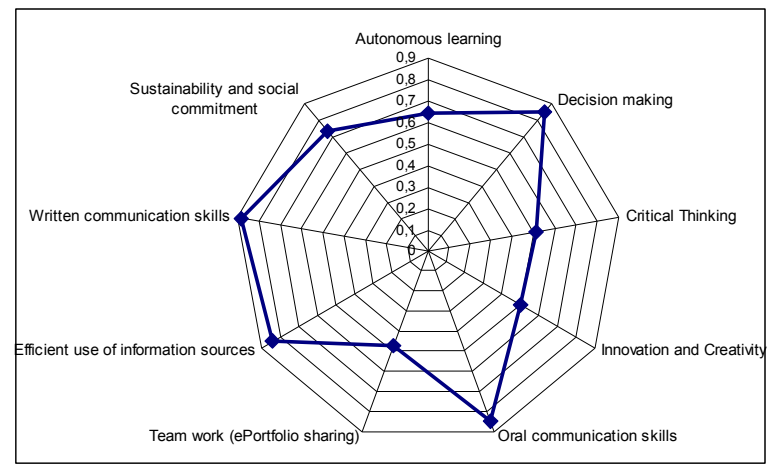

Figura 5. Rúbrica de la evaluación de las competencias de la UPC ETSEIAT (Students' set rubrics assessment)

\section{Discussion}

The teaching innovation experience carried out in the two subjects provides us with both quantitative and qualitative data on how professors can assess the exact degree of acquisition of students' competences, as is the case of communication skills, synthesis and analysis abilities, etc. Such an evaluation can be easily done during the process of students' e-Portfolio development through the application of a set generic criteria that will allow our teaching staff to follow-up students' progress closely and observe their steady competences' acquisition (See Appendix).

At this stage, we could compare the evidence that we have obtained carrying out the present study with the qualitative results shown in reference [3]. Chun argued on the usefulness of the e-Portfolio as a tool that aids reaching learning objectives as students are asked to gather, assess and reflect on their own evidence, namely different tasks and homework, their own reflection on learning and competences' acquisition or the implementation of new concepts. All this material that we find collected in students' ePortfolios allows us, professors, to identify their level of competence development throughout students' learning process.

Furthermore, we can confirm that our students use Kolb's (1984) three ways of learning through the ePortfolio's development as they all: a) apply the knowledge learnt during the subject (specific experiences \& self-learning), b) generate reflection and personal views during its creation and, more precisely, towards the case/project they are working on (abstract conceptualization \& critical thinking) and c) explore and develop logic skills (experimentation \& decision making). These three types of learning are reflected in the varied evidence provided in each student's ePortfolio besides from the data gathered concerning competence assessment (through the questionnaire) which show the following results: decision making $(84 \%)$, critical thinking (51\%) and autonomous learning $(64 \%)$.

In this sense, we must indicate that the numerous outcome from students' e-Portfolio evidence, in this experience, results from a continuous feedback that every student has had from other classmates and/or professors during the process of this methodological tool creation. Hence, the importance of each student sharing his/her e-Portfolio with his/her peers (in fact, $47 \%$ of them share it). But it is also important to bear in mind that it is necessary to measure the impact the ePortfolio has during every student learning process. As for this last indicator is concerned, we should explain here that it is assessed through the survey and it shows that $33 \%$ of the professors in the UPC use collaborative tools inside their classrooms and $77 \%$ of them sense the usefulness of such tools as a very effective teaching methodology to develop students' competences.

Although the present pilot study has only been focused on two different subjects, we could claim that its teaching methodology has a great potential in terms of a complementary device to assess university students' competences. So as to accurately measure its efficiency 4 factors are highly recommended: (1) a very precise strategic planning to suit the needs, objectives and level of competences for each subject, (2) teaching staff's motivation toward the implementation of this methodological innovation, (3) the development of generic rubrics for each level of competency that could be generalized and applied to all subjects and, finally, (4) the constant support from the teaching center and/or school. To sum up, in the 
following lines we include a selection of our students' reflection on the experience carried out in ETSEIAT:

\begin{abstract}
"My reflection about this subject is positive: Firstly, because I have learned and practised English, and I think that it is very important for the work life, at university and in our private lives. It is our present and future. In many universities lessons are in English and I think that it is better for students' professional future.
\end{abstract}

Secondly, because I have learned a new Google application (Google Sites), and I think that I can continue using this setting in the future, for example in Projects subject.Thirdly, I liked the MQ2 subject because we have solved real problems in our life, not hypothetical things that we don't see its application. On the other hand, I think that we need more time working in the e-Portfolio..."

"In my first class "Projects", it was when I was firstly introduced to the e-Portfolio, which I found very useful.

"I may have not only acquired technical knowledge, but I know now how to express myself as a serious and dynamic student"

In general, our students think that this experience has been positive and they also see the usefulness of the e-Portfolio both at a curricular and personal level. However, they believe that they have to devote more time to get the most of this new methodological tool.

\section{Conclusion}

The main challenge of the present project has been planning how to incorporate the appropriate teaching methodology for the e-Portfolio's implementation in two subjects within the ETSEIAT curricula. Not to mention, the later diffusion of its usefulness and the possibility to implement this methodological tool within the new degrees offered at the UPC. The use of the e-Portfolio seems to be a perfect complementary way to assess students' competences, providing professors with a great and precise follow-up of their students, making their knowledge acquisition easier and assessing their learning process throughout the whole Grau (new degree system). Besides, this methodological tool can be easily implemented in a wide range of academic subjects using a single platform owned by each student.

Both the emergence and the use of collaborative environments, which enhance sharing information in the net as well as in several teaching platforms (e.g. $\mathrm{BSCW}$, Atenea) within the universities curricula, together with the recognition of the e-Portfolio's usefulness in students' learning processes, validates our hypothesis in considering this methodological innovation as a possible teaching tool to aid students' competences development assessment.

The present article, then, shows qualitative and quantitative date that remark the efficiency of the ePortfolio as a complementary tool for students' assessment. We have to keep in mind, though, that for this innovation experience to succeed inside the classroom professors have to encourage students' participation taking into account their needs and attitudes. Therefore, some questions have to be correctly addressed beforehand, such as students' level of acceptance, motivation, assessment and the technology used to increase their participation. In order to make the implementation work, students have to handle good examples, understand the benefits, and be familiar with the objectives set and how the new methodological tool will help them in their learning. But, most of all, we should keep students motivated all the time as they usually become actively involved when they know the results of an experience in advance (i.e. the way they will be assessed: using rubrics). However, we must also leave a margin for them to develop their critical thinking and to get to know how the tool is used as many students have difficulties when coping with new software. Not to mention, privacity issues may arise in here. In addition, this innovation has to be extremely flexible to suit the level of each student, allowing his/her steady improvement in skills and becoming more confident with time.

\section{References}

[1] R. J. Beck, N. L. Livne, and S. L. Bear, "Teachers' selfassessment of the effects of formative and summative electronic portfolios on professional development", European Journal of Teacher Education, vol. 28(3), 2005, pp. 221-244.

[2] M. Bhattacharya, and H. Hartnett, "E-Portfolio asssessment in Higher Education", proceedings of the 37th annual ASEE/IEEE Frontiers in Education Conference on Milwaukee, T1G-19, October 2007.

[3] M. Chun, "Looking where the light is better: A review of the literature on assessing higher education quality", Peer Review, Winter/ Spring 2002. [Online, available: www.aacu.org/peerreview/pr-sp02/pr-sp02feature3.cfm, accessed February, 2010].

[4] eCDF ePortfolio Project Steering Committee, "A Review Of The Literature On Portfolios And Electronic Portfolios", Creative Commons Attribution, 2006. [Online, available: http://akoaotearoa.ac.nz/download/ng/file/group-996/n2620eportfolio-research-report.pdf, accessed February, 2010].

[5] E. Heinrich, M. Bhattacharya, and R. Rayudu, "Preparation for lifelong learning using eportfolios", European Journal of Engineering Education, vol. 32(6), 2007, pp.653-663.

[6] V. Klenowski, S. Askew, and E. Carnell, "Portfolios for learning, assessment and professional development in higher 
education", assessment and Evaluation in Higher Education, vol. 31(3), 2006, pp. 267-286.

[7] L. L. Lynch, and P. Purnawarman, "Electronic portfolio assessments in US educational and instructional technology programs: Are they supporting teacher education?", TechTrends, vol. 48(1), 2004, pp. 50-56.

[8] M. Raman, T. Ryan, and L. Olfman, "Designing knowledge management systems for teaching and learning with wiki technology", Journal of Information Systems Education, Vol. 16(3), 2005, pp. 311-320.

[9] W. Richardson, Blogs, Wikis, Podcasts, and Other Powerful Web Tools for Classrooms, Corwin Press, Thousand Oaks, CA., 2006. 


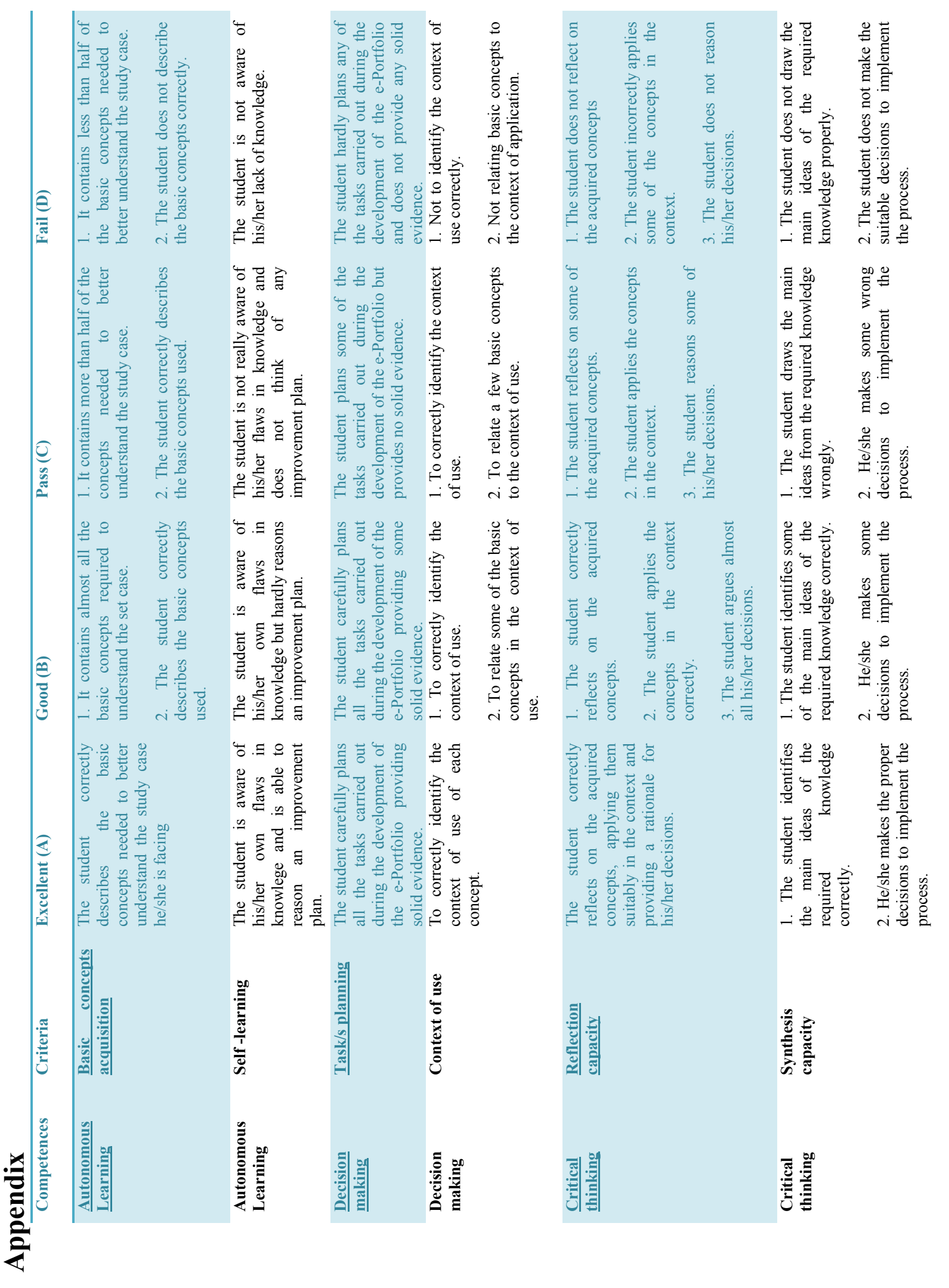




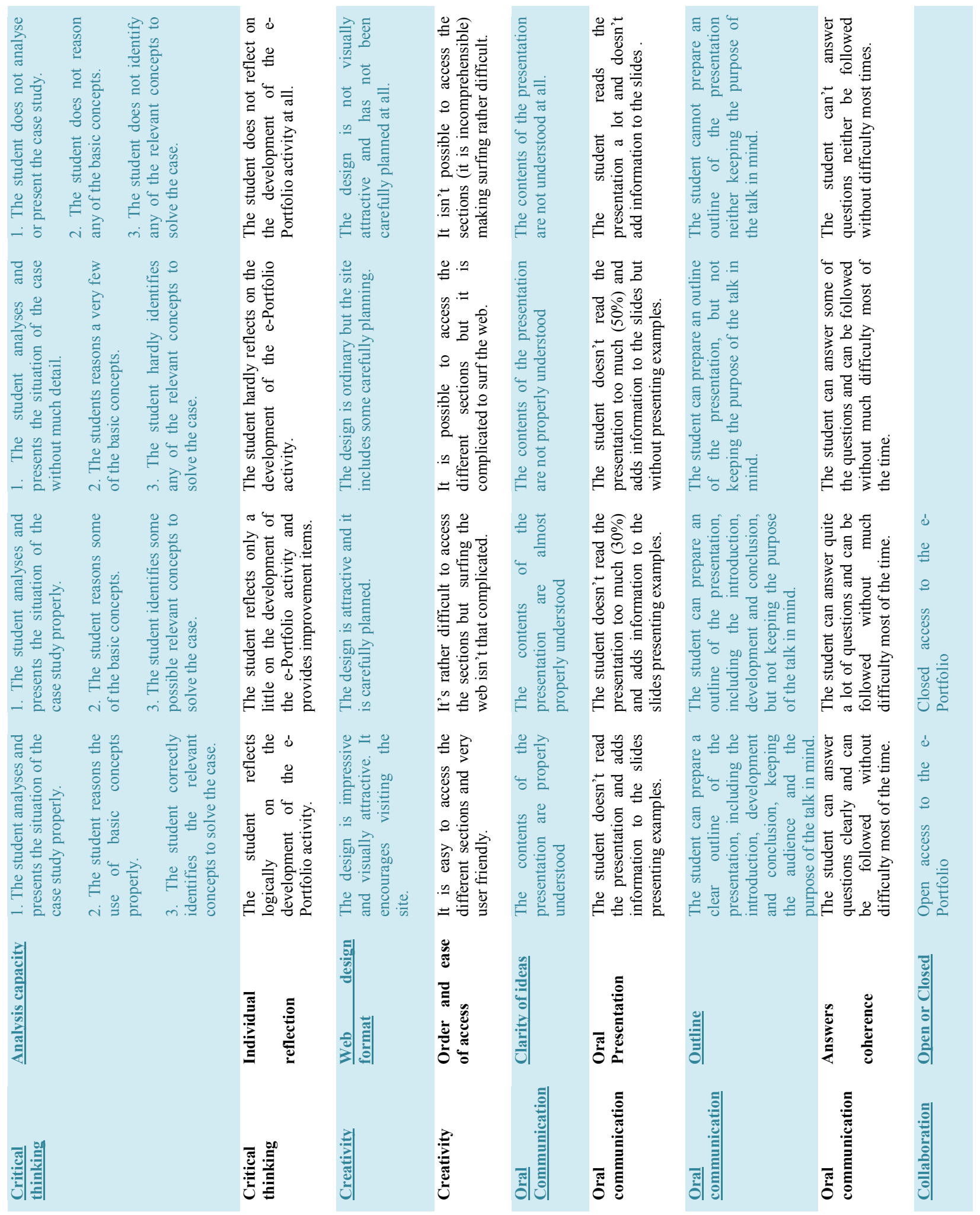




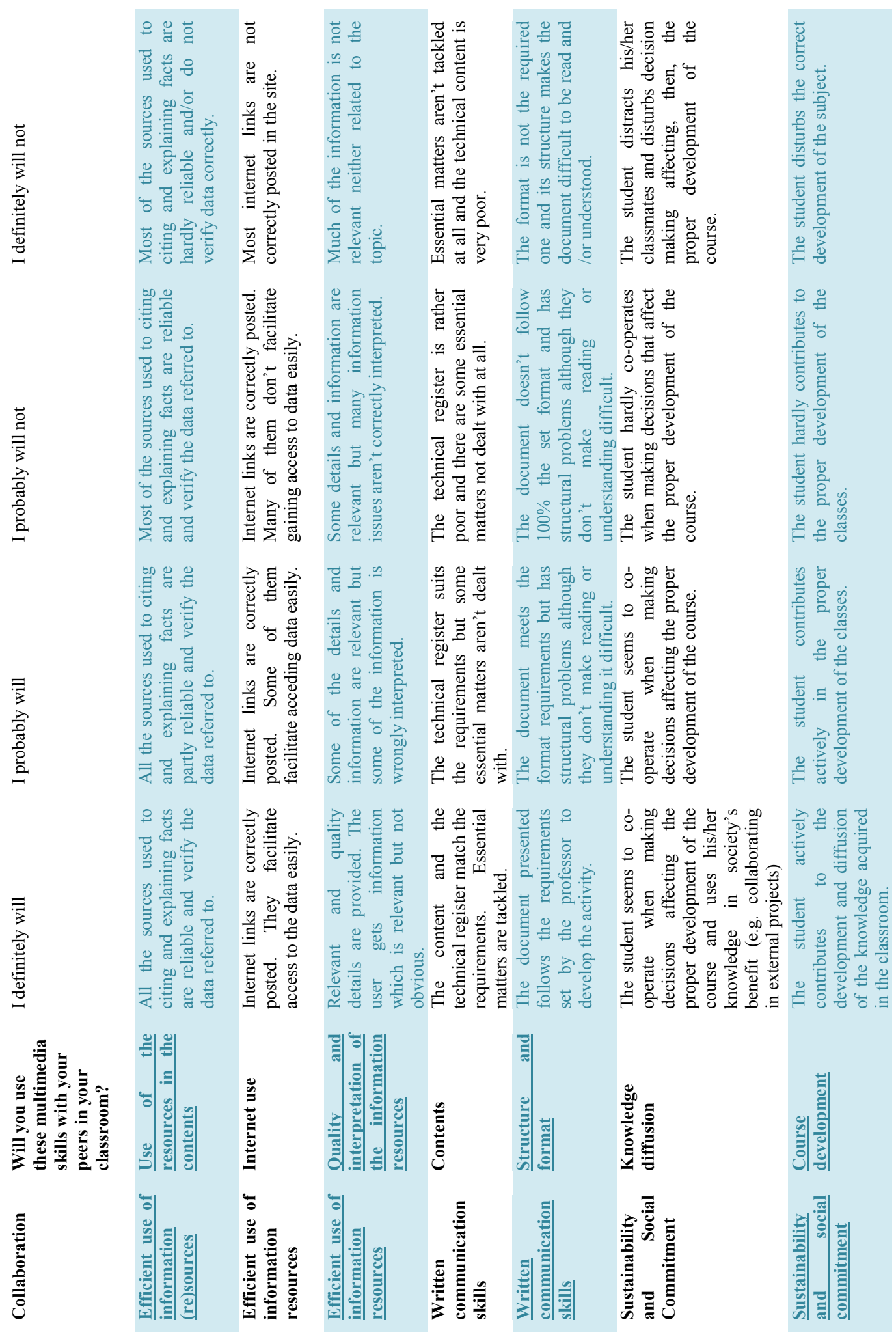

